\title{
Sulfur metabolisms in epsilon- and gamma-Proteobacteria in deep-sea hydrothermal fields
}

\author{
Masahiro Yamamoto ${ }^{1,2 *}$ and Ken Takai ${ }^{1,2}$ \\ 1 Subsurface Geobiology Advanced Research Project, Japan Agency for Marine-Earth Science and Technology, Yokosuka, Japan \\ 2 Precambrian Ecosystem Laboratory, Japan Agency for Marine-Earth Science and Technology, Yokosuka, Japan
}

\section{Edited by:}

Niels-Ulrik Frigaard, University of Copenhagen, Denmark

Reviewed by:

Masaharu Ishii, University of Tokyo, Japan

Biswarup Mukhopadhyay, Virginia Bioinformatics Institute, USA

*Correspondence:

Masahiro Yamamoto, Institute of Biogeosciences, Japan Agency for Marine-Earth Science and Technology, 2-15 Natsushima-cho, 237-0061 Yokosuka, Japan.

e-mail:myama@jamstec.go.jp
In deep-sea hydrothermal systems, super hot and reduced vent fluids from the subseafloor blend with cold and oxidized seawater. Very unique and dense ecosystems are formed within these environments. Many molecular ecological studies showed that chemoautotrophic epsilon- and gamma-Proteobacteria are predominant primary producers in both free-living and symbiotic microbial communities in global deep-sea hydrothermal fields. Inorganic sulfur compounds are important substrates for the energy conservative metabolic pathways in these microorganisms. Recent genomic and metagenomic analyses and biochemical studies have contributed to the understanding of potential sulfur metabolic pathways for these chemoautotrophs. Epsilon-Proteobacteria use sulfur compounds for both electron-donors and-acceptors. On the other hand, gamma-Proteobacteria utilize two different sulfur-oxidizing pathways. It is hypothesized that differences between the metabolic pathways used by these two predominant proteobacterial phyla are associated with different ecophysiological strategies; extending the energetically feasible habitats with versatile energy metabolisms in the epsilon-Proteobacteria and optimizing energy production rate and yield for relatively narrow habitable zones in the gamma-Proteobacteria.

Keywords: deep-sea hydrothermal vents, energy metabolism, chemoautotroph

\section{INTRODUCTION}

The deep-sea hydrothermal system is one of the most extreme environments on Earth. It is characterized by darkness, high pressures, and steep physical and chemical gradients formed in mixing zones between hot hydrothermal vent fluid and cold deep-sea water. Very unique and dense communities of invertebrates are sustained in absence of a photosynthetic energy source (Dubilier et al., 2008). Almost all vent-endemic animals are strongly associated with the primary production of the endo- and/or episymbiotic chemoautotrophic microorganisms (Jeanthon, 2000). With the discovery of deep-sea hydrothermal ecosystem in 1977, it had been proposed that hydrogen sulfide-oxidizing and oxygenreducing chemoautotrophs potentially sustain the primary production in these unique ecosystems (Kvenvolden et al., 1979). However, anoxic hydrothermal fluids contain several reduced compounds such as $\mathrm{H}_{2}, \mathrm{CH}_{4}$, and reduced metal ions in addition to $\mathrm{H}_{2} \mathrm{~S}$ (Jannasch and Mottl, 1985). Recent cultivation studies have demonstrated that these chemicals are all used as energy sources for chemoautotrophs (Jannasch and Mottl, 1985; Nakagawa et al., 2005; Campbell et al., 2006; Emerson et al., 2007), indicating the great diversity of chemoautotrophic energy metabolic processes in the ecosystems. Hydrogen gas $\left(\mathrm{H}_{2}\right)$ is one of the most important energy sources, and the hydrogen-dependent ecosystems may represent analogs for the earliest biological communities on Earth (Takai et al., 2004, 2006b; Nealson et al., 2005).

Hydrogen sulfide or sulfide is primarily supplied via high temperatures of seawater-rock interactions in the subseafloor hydrothermal reaction zones (Jannasch and Mottl, 1985). Thermodynamic modeling indicated that the hydrogen sulfide or sulfide abundantly contained in the hydrothermal fluids represented the dominating energy source in the mesophilic deep-sea vent chemoautotrophic ecosystems (McCollom and Shock, 1997). In addition, partially oxidized inorganic sulfur compounds such as polysulfide, elemental sulfur, and thiosulfate are generated in the in situ mixing zones, and serve as both electron donor and acceptor in a variety of energy metabolisms. The chemical and microbial oxidation and reduction reactions of sulfur compounds probably establish the overall complex sulfur metabolism network in the ecosystem. This article reviews the representative microbial components capable of utilizing the inorganic sulfur compounds as the energy sources in the deep-sea hydrothermal environments and highlights the biochemical and genetic components of their metabolisms. In addition, the possible segregation of different sulfur metabolic pathways and their host chemoautotrophic Proteobacteria associated with the physical and chemical transition in the mixing zones of the deep-sea hydrothermal environments is discussed.

\section{MICROBIAL COMMUNITIES IN DEEP-SEA HYDROTHERMAL FIELDS}

Recent culture-independent analyses of the both symbiotic and free-living microbial communities in the various deep-sea hydrothermal environments have revealed a great phylogenetic diversity of Archaea and Bacteria (Takai et al., 2006a); these analyses have also indicated a predominance in biomass of members within the gamma-Proteobacteria and epsilon-Proteobacteria (Stewart et al., 2005; Suzuki et al., 2005; Urakawa et al., 2005; Campbell et al., 2006; Nakagawa and Takai, 2008; Table 1). Based 


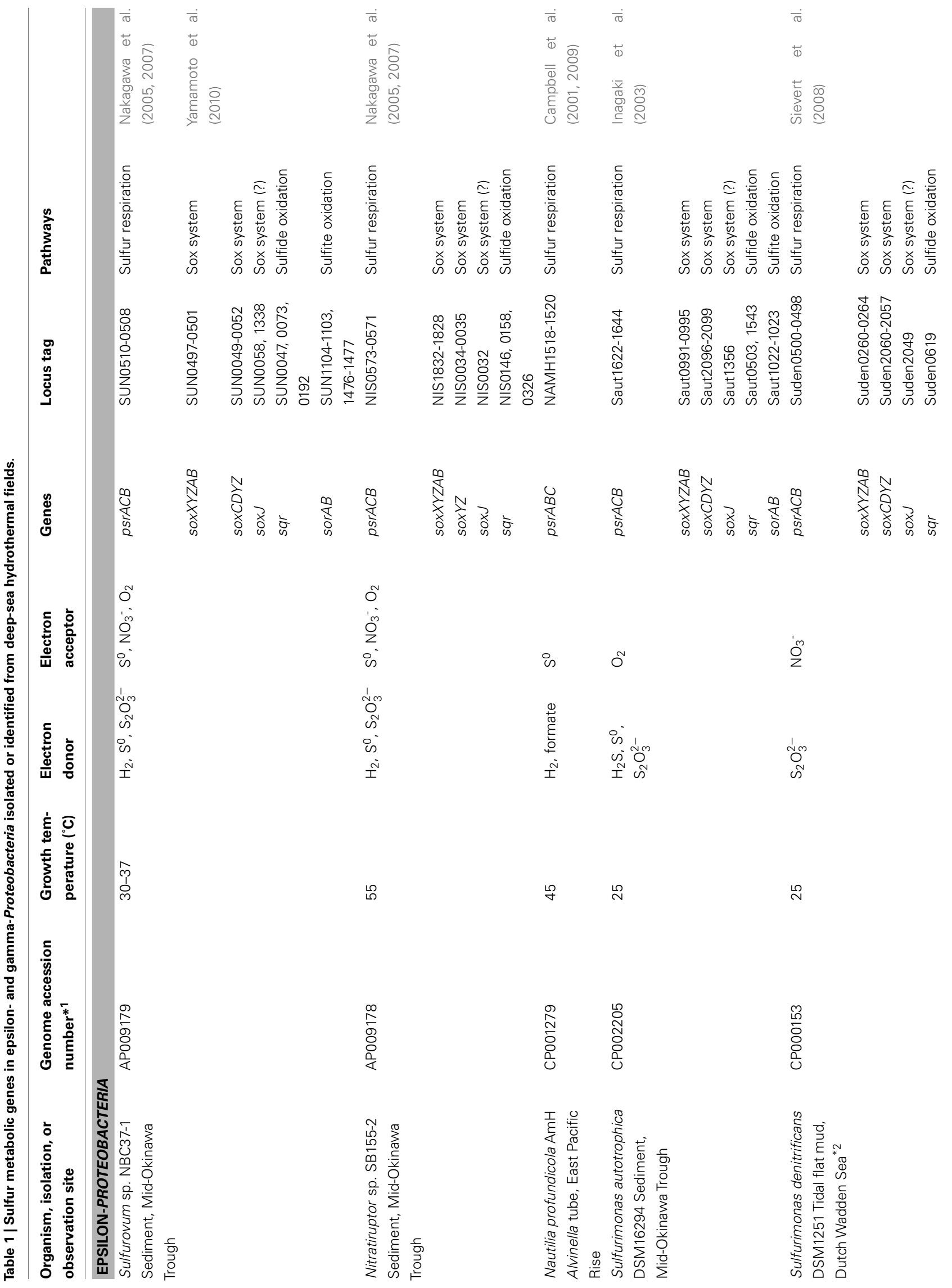




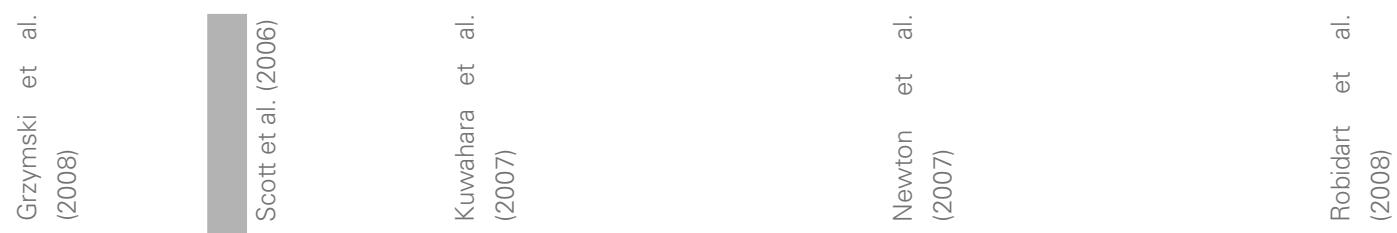

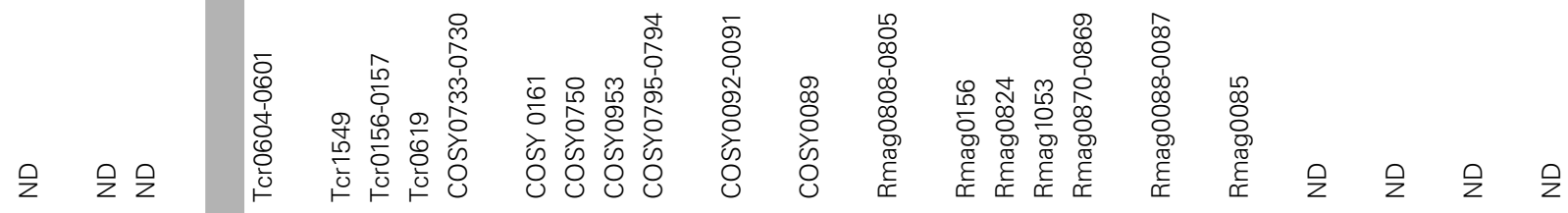

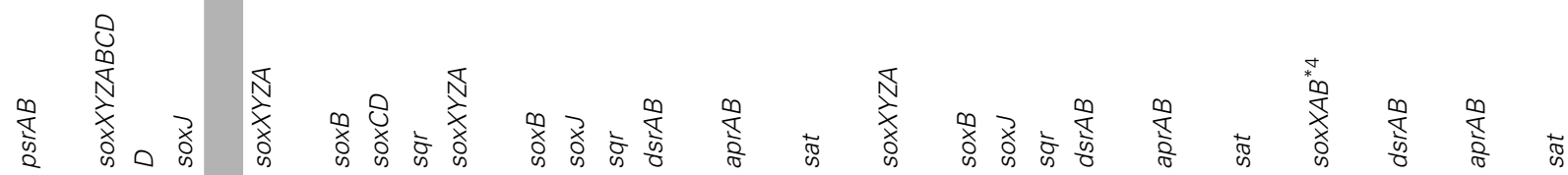

公

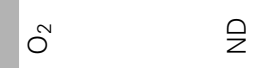

之

之

is

is

之

之

六

१

$\stackrel{0}{0}$
$\stackrel{0}{0}$

₹

之

定

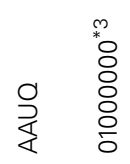

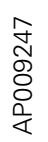

$\infty$
0
0
8
0
0
0

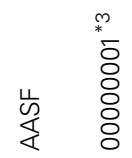

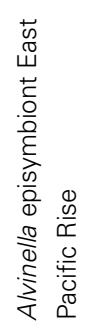
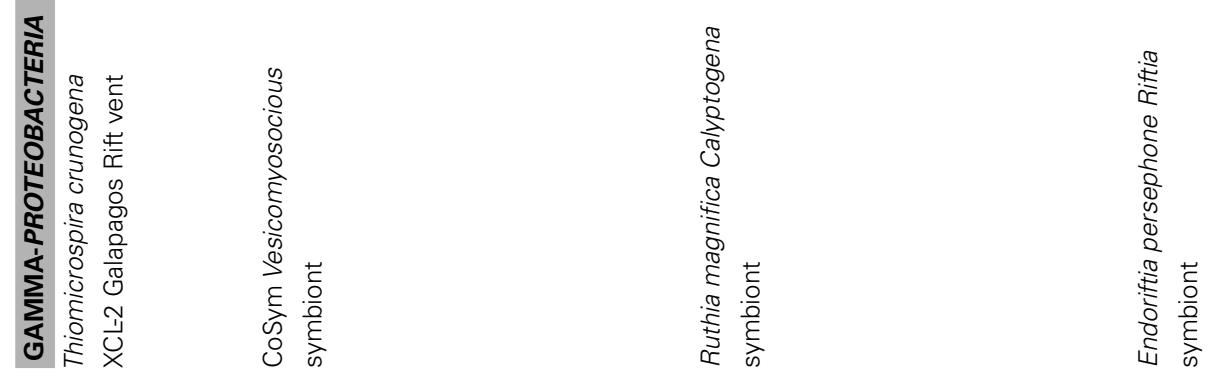


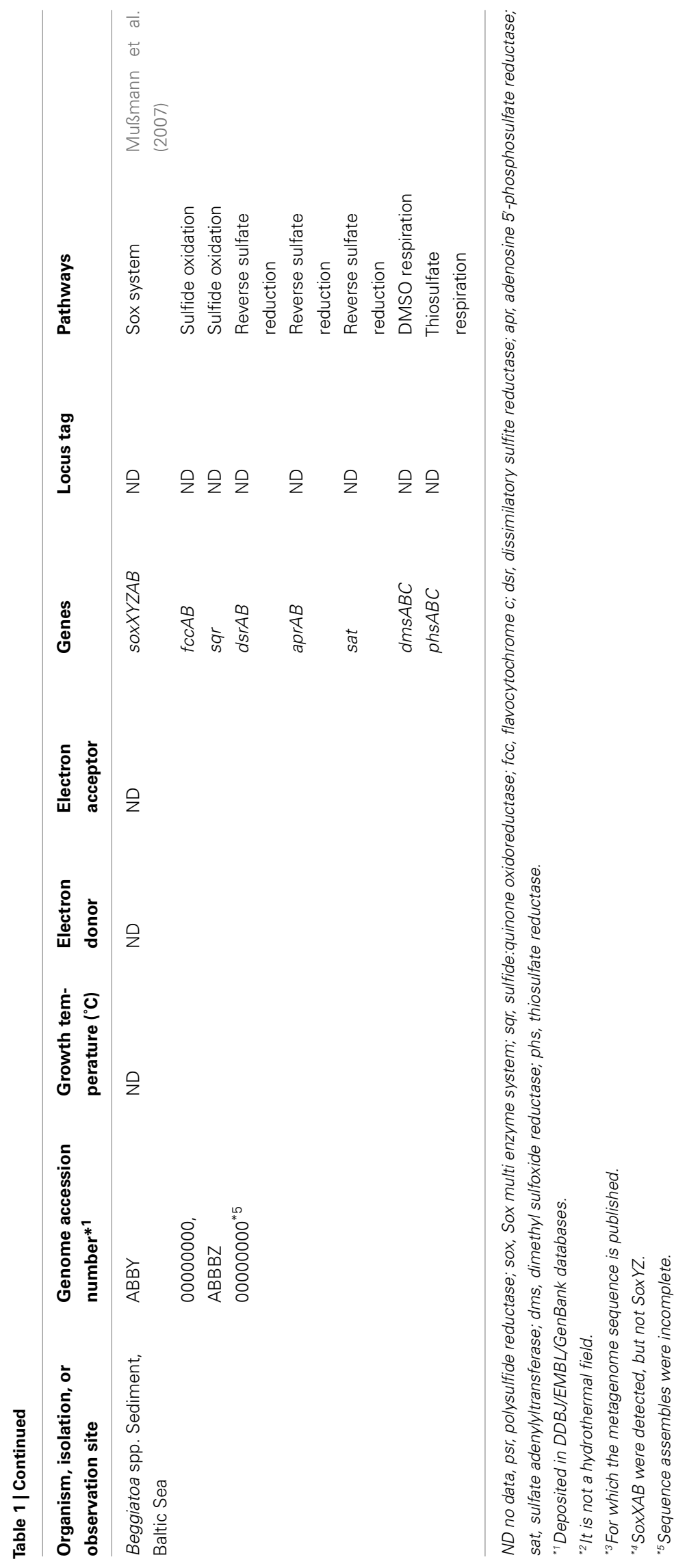


on the culture-dependent characterization and genetic components analyses, these Proteobacteria are found to be chemoautotrophs strongly associated with utilization of inorganic sulfur compounds (Durand et al., 1993; Inagaki et al., 2003, 2004; Takai et al., 2003b, 2006a,c). Therefore, the sulfur-related energy metabolisms in these Proteobacteria are important traits for understanding ecology and biogeochemistry in deep-sea hydrothermal vent ecosystems.

\section{MICROBIAL SULFUR METABOLIC PATHWAYS FOR ENERGY CONSERVATION}

Inorganic sulfur compounds are used as both electron donor and acceptor by microorganisms. Sulfur-oxidation pathways have been well studied biochemically in anaerobic phototrophs (e.g., Chlorobium and Allochromatium), facultatively chemoautotrophic Proteobacteria (e.g., Acidithiobacillus and Paracoccus) and Sulfolobales (e.g., Sulfolobus and Acidianus; Friedrich, 1998; Kletzin et al., 2004; Friedrich et al., 2005; Frigaard and Dahl, 2009). Bacterial sulfuroxidation pathways under the neutral $\mathrm{pH}$ are generally classified into two different types: (1) reverse sulfate reduction, and (2) Sox multienzyme system. Reverse sulfate reduction is reversal of sulfate reduction pathway, in which sulfide is oxidized to sulfate via sulfite. This pathway uses the same families of enzymes as of the sulfate reduction pathway, such as dissimilatory sulfite reductase (Dsr), adenylphosphosulfate reductase (Apr), and sulfate adenylyltransferase (Sat; Kappler and Dahl, 2001). Sox multienzyme complex catalyzes oxidation of inorganic sulfur compounds. Four protein components, SoxYZ, SoxXA, SoxB, and SoxCD are required for complete oxidation of sulfide and thiosulfate to sulfate (Complete Sox pathway; Friedrich et al., 2001). However, the sulfur oxidizers that possess the $\operatorname{sox} Y Z X A B$ genes but not sox $C D$ have often been reported (Friedrich et al., 2005). It is considered that SoxCD acts as sulfur dehydrogenase. Sox system without SoxCD is able to oxidize sulfite and sulfone group $\left(-\mathrm{SO}_{3}^{-}\right)$in thiosulfate, but not sulfide, elemental sulfur, and sulfane sulfur $\left(-\mathrm{S}^{-}\right)$ in thiosulfate (Friedrich et al., 2001). In addition to these two sulfur-oxidation pathways, several enzymes have been proposed to oxidize inorganic sulfur compounds, including sulfide:quinone oxidoreductase (Sqr), flavocytochrome $c$ (Fcc), and sulfite oxidase (SO), though the exact physiological functions are still debated. Sqr is a single-subunit flavoprotein that catalyzes oxidation of sulfide to elemental sulfur (Shahak and Hauska, 2008; Frigaard and Dahl, 2009). Recent protein structural study divided Sqr family into six groups (Marcia et al., 2010). These different types of Sqr probably have different mechanisms and physiological roles (Chan et al., 2009; Gregersen et al., 2011; Holkenbrink et al., 2011). Fcc also catalyzes oxidation of sulfide to elemental sulfur, but electrons are transferred to the level of cytochrome $c$ (Oh-oka and Blankenship, 2004). Fcc consists of a flavoprotein subunit, FccB, and a c-type cytochrome subunit, FccA (Kusai and Yamanaka, 1973; Reinartz et al., 1998). The soxEF genes conserved in the sox gene clusters are homologous genes of the $f c c A B$ genes (Friedrich et al., 2008). The soxJ gene is a homologous gene of $f c c B / \operatorname{soxF}$, that does not cluster with a homolog of $f c c A / \operatorname{soxE}$ (Gregersen et al., 2011). SO is a molybdenum enzyme and catalyzes the direct oxidation of sulfite to sulfate (Kappler and Dahl, 2001). Acidophilic sulfur-oxidizing bacteria and archaea use different sulfur-oxidation pathways that will not be further described here (see Ghosh and Dam, 2009).

Sulfur-reduction pathways can be classified into two types based on the substrates: (1) sulfur-reduction (sulfur respiration), and (2) sulfate reduction (sulfate respiration). Sulfur-reduction pathways have been intensively studied in gastrointestinal epsilonProteobacterium, Wolinella succinogenes (Wolin et al., 1961; Hedderich et al., 1999). Sulfur-reduction is catalyzed by polysulfide reductase (Psr), in which the actual substrate of the reaction is polysulfide but not elemental sulfur (Pfennig and Biebel, 1986). Sulfate reducing bacteria are found in several different phylogenetic lines (e.g., delta-Proteobacteria, Clostridia, Thermodesulfobacteria, and Nitrospirae; Muyzer and Stams, 2008). Sat, Apr, and Dsr catalyze the reduction of sulfate to sulfide.

\section{SULFUR METABOLISM IN EPSILON-PROTEOBACTERIA IN DEEP-SEA HYDROTHERMAL FIELDS}

The most well known epsilon-Proteobacteria are gastrointestinal pathogens such as Helicobacter and Campylobacter. They are heterotrophic and do not have inorganic sulfur metabolic pathways. The genus Wolinella isolated from cattle rumen can reduce elemental sulfur to hydrogen sulfide (Wolin et al., 1961).

There are many reports that chemoautotrophic epsilonProteobacteria are predominant in sulfidic environments such as deep-sea hydrothermal and subsurface environments (Takai et al., 2004; Campbell et al., 2006; Nakagawa and Takai, 2008). Recently, whole genome sequences of five strains of marine epsilon-Proteobacteria, i.e., Sulfurovum sp. NBC37-1, Nitratiruptor sp. SB155-2, Nautilia profundicola AmH, Sulfurimonas autotrophica DSM16294 isolated from deep-sea hydrothermal fields, and $S$. denitrificans DSM1251 isolated from a coastal wetland, have been determined (Nakagawa et al., 2007; Sievert et al., 2008; Campbell et al., 2009; Table 1). Moreover, the metabolism of episymbiontic epsilon-Proteobacterium in a polychaete worm was analyzed by metagenomic analysis (Grzymski et al., 2008). In addition, several biochemical studies on sulfur metabolic pathways in deep-sea epsilon-Proteobacteria have also been reported (Takai et al., 2005; Yamamoto et al., 2010).

Genetic and enzymatic components characterized by the genomic and biochemical analyses of deep-sea epsilonProteobacteria have facilitated considerable progress in determining the possible sulfur metabolism pathways of the deep-sea chemoautotrophic epsilon-Proteobacteria (Table 1). The deep-sea epsilon-Proteobacteria characterized so far possess (1) a hydrogenoxidizing sulfur respiration pathway using hydrogenase and polysulfide reductase (Psr). And the epsilon-Proteobacteria except for $N$. profundicola $\mathrm{AmH}$, possess (2) a sulfur compounds-oxidizing oxygen/nitrate-respiration pathway using the Sox multienzyme system. Both of the Sox systems coupled with and without SoxCD have been found. The sox genes are not organized in a single region, but at least in two separated regions of the $\operatorname{soxXYZAB}$ and $\operatorname{sox}(C D) Y X$ genes. One or more soxF gene was conserved in each sox gene cluster. Sulfurovum sp., Nitratiruptor sp., and $S$. autotrophica have several sqr genes. Two sets and one set of the sor $A B$ genes coding SO were observed in Sulfurovum sp. and $S$. autotrophica, respectively. No gene for sulfur-oxidation pathways was found in $N$. profundicola. In addition to the sulfur metabolic 
pathways, many deep-sea epsilon-Proteobacteria are capable of chemoautotrophic growth without sulfur compounds using a third metabolic pathway: (3) a hydrogen-oxidizing oxygen/nitratereduction pathway (Figure 1). The bacterial members that can use sulfur compounds as both electron acceptors and donors are identified only in the phyla of epsilon-Proteobacteria and Aquificae, both of which predominantly inhabit in deep-sea hydrothermal environments. This may provide an important clue into how the versatile energy metabolic pathways are associated with the energetic advantages adapted to the dynamic and transient environmental conditions in the mixing zones of the hydrothermal vent environments.

\section{SULFUR METABOLISM IN GAMMA-PROTEOBACTERIA IN DEEP-SEA HYDROTHERMAL FIELDS}

Gamma-proteobacterial symbionts with invertebrates have never been isolated from deep-sea hydrothermal vents. Furthermore only a couple of free-living sulfur-oxidizing gamma-Proteobacteria have been isolated from deep-sea hydrothermal fields (Kuever et al., 2002; Takai et al., 2006c, 2009). Unculturable gammaproteobacterial sulfur-oxidizing endosymbionts are classified into three groups based on their host invertebrates: symbionts of (1) Bathymodiolus mussels and Calyptogena clams, (2) Alviniconcha gastropods, and (3) gastropods (e.g., Ifremeria) and tubeworms (Nakagawa and Takai, 2008). In recent years, two genome sequences of sulfur-oxidizing symbionts in Calyptogena have been

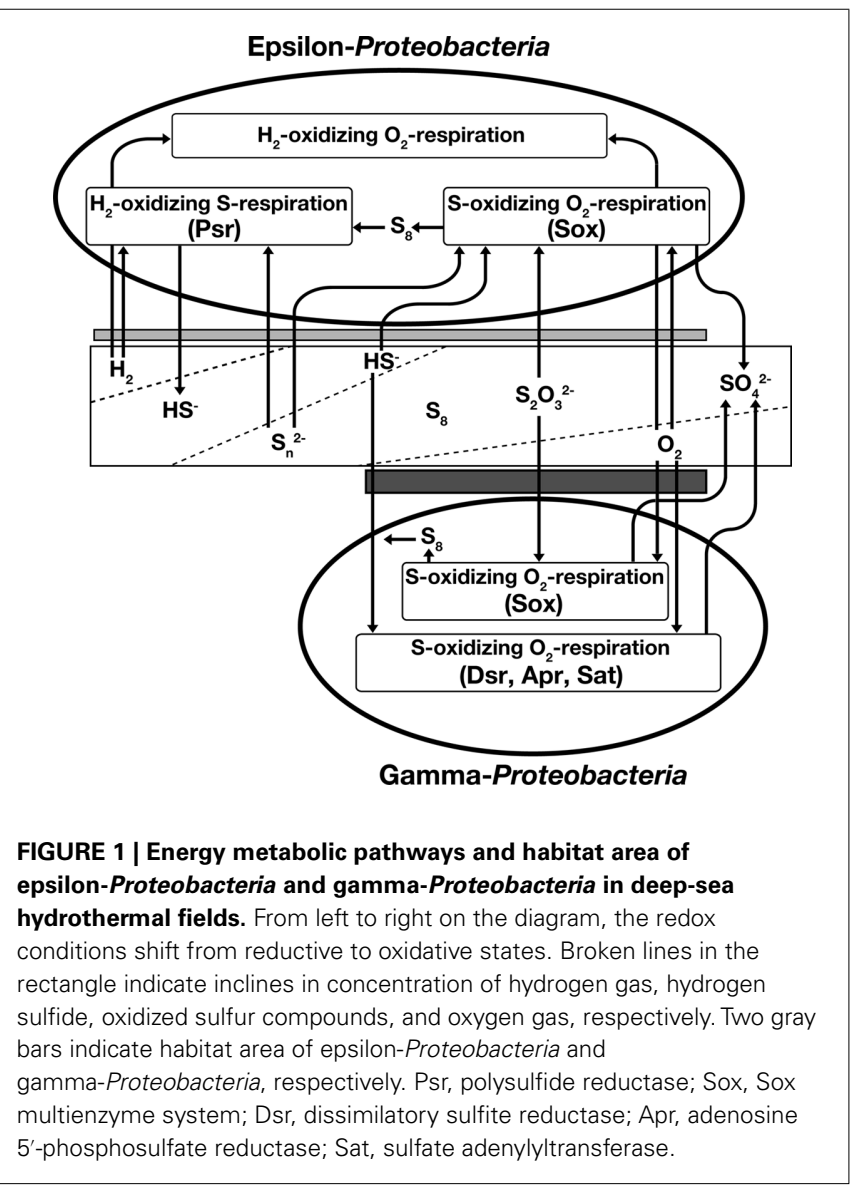

published (Kuwahara et al., 2007; Newton et al., 2007; Table 1). Moreover, the metabolisms of symbiont in tubeworm were analyzed by metagenomic analysis (Robidart et al., 2008). In addition, a whole genome sequence of free-living sulfur-oxidizing gammaProteobacterium, Thiomicrospira crunogena XCL-2 was also published (Scott et al., 2006). Putative metabolic pathways in Beggiatoa sp. from marine sediments had also analyzed by using incomplete genome sequence (Mußmann et al., 2007). From these genomebased genetic characteristics, we can develop a preliminary outline of representative sulfur-related energy metabolisms in the deepsea hydrothermal gamma-Proteobacteria, which possess two different sulfur-oxidization pathways: (1) the reverse sulfate reduction using Dsr, Apr, and Sat, and (2) the Sox multienzyme system without SoxCD (Figure 1). T. crunogena XCL-2, however, is an exception, in which no gene for the reverse sulfate reduction pathway was found. Moreover, this organism has the soxCD genes separated from other sox genes. In contrast, functional genes amplification studies suggested that hydrothermal gamma-Proteobacteria use the reverse sulfate reduction pathway, but not the Sox pathway (Hügler et al., 2010). These results indicate that either of the two distinct sulfur-oxidization pathways is dispensable. Both of these pathways require $\mathrm{O}_{2}$ as a terminal electron acceptor in most cases. This fact indicates that the relatively reductive environment $\left(\mathrm{O}_{2}\right.$-depleted condition) is inhibitory for the growth of deep-sea chemoautotrophic gamma-Proteobacteria due to the limitation of primary electron acceptor despite an increasing abundance of electron-donors (reduced sulfur compounds). Thus, it is predicted that the metabolically habitable spaces of deep-sea chemoautotrophic gamma-Proteobacteria strictly requiring co-existence of reduced sulfur compounds and $\mathrm{O}_{2}$ are much more limited than those of deep-sea epsilon-Proteobacteria in the mixing zones of hydrothermal environments. Conversely, however, it seems likely that the genomic installation and the biochemical operation of two different sulfur-oxidizing pathways in the deep-sea chemoautotrophic gamma-Proteobacteria are kinetically advantageous if both the reduced sulfur compounds and $\mathrm{O}_{2}$ are steadily supplied into the habitats. Particularly for the gamma-proteobacterial sulfur-oxidizing symbionts, the host invertebrates would prepare the metabolically suitable habitats in and around the bodies in the mixing zones of deep-sea hydrothermal environments (Arp and Childress, 1983; Zal et al., 1998; Numoto et al., 2005). This may be one of the possible rationales for the domination of deepsea gamma-proteobacterial sulfur-oxidizing chemoautotrophs in symbiotic communities in deep-sea hydrothermal environments. All deep-sea sulfur-oxidizing gamma-Proteobacteria possess one sqr gene in the genome, except for the metagenome of Riftia symbiont. Therefore, Sqr probably has an important role for the sulfur-oxidation in the organisms. It is interesting that genes for sulfur compound (thiosulfate and dimethyl sulfoxide) respiration were found in genome of Beggiatoa sp. (Mußmann et al., 2007). This is in accordance with previous results in Beggiatoa alba that can reduce stored elemental sulfur to overcome short-term anoxic conditions (Nelson and Castenholz, 1981; Schmidt et al., 1987).

\section{CONCLUDING REMARKS}

In this review, we described the sulfur-related energy metabolisms of epsilon- and gamma-Proteobacteria dominating the microbial 
communities in the global deep-sea hydrothermal environments. Most of the metabolic characteristics summarized in this article are based on the reconstruction of genetic components in the genomes determined for only a few representative species. Further genetic and biochemical variability associated with the sulfur-related energy metabolisms will be clarified in many species of deepsea hydrothermal vent epsilon- and gamma-Proteobacteria in the future. Surely, the investigation of other inorganic sulfur metabolizing groups of microbial components such as sulfate-reducers (delta-Proteobacteria, Thermodesulfobacteria, and Deferribacteres) and sulfur-reducing thermophiles (Aquificae, Thermococcaceae,

\section{REFERENCES}

Arp, A. J., and Childress, J. J. (1983). Sulfide binding by the blood of the hydrothermal vent tube worm Riftia pachyptila. Science 219, 295-297.

Campbell, B. J., Engel, A. S., Porter, M. L., and Takai, K. (2006). The versatile epsilon-proteobacteria: key players in sulphidic habitats. Nat. Rev. Microbiol. 4, 458-468.

Campbell, B. J., Jeanthon, C., Kostka, J. E., Luther, G. W. III, and Cary, S. C. (2001). Growth and phylogenetic properties of novel bacteria belonging to the epsilon subdivision of the Proteobacteria enriched from Alvinella pompejana and deep-sea hydrothermal vents. Appl. Environ. Microbiol. 67, 4566-4572.

Campbell, B. J., Smith, J. L., Hanson, T. E., Klotz, M. G., Stein, L. Y., Lee, C. K., Wu, D., Robinson, J. M., Khouri, H. M., Eisen, J. A., and Cary, S. C. (2009). Adaptations to submarine hydrothermal environments exemplified by the genome of Nautilia profundicola. PLoS Genet. 5, e1000362. doi: 10.1371/journal.pgen.1000362

Chan, L. K., Morgan-Kiss, R. M., and Hanson, T. E. (2009). Functional analysis of three sulfide:quinone oxidoreductase homologs in Chlorobaculum tepidum. J. Bacteriol. 191, 1026-1034.

Dubilier, N., Bergin, C., and Lott, C. (2008). Symbiotic diversity in marine animals: the art of harnessing chemosynthesis. Nat. Rev. Microbiol. 6, 725-740.

Durand, P., Reysenbach, A.-L., Prieur, D., and Pace, N. (1993). Isolation and characterization of Thiobacillus hydrothermalis sp. nov., a mesophilic obligately chemolithotrophic bacterium isolated from a deep-sea hydrothermal vent in Fiji Basin. Arch. Microbiol. 159, 39-44.

Emerson, D., Rentz, J. A., Lilburn, T. G., Davis, R. E., Aldrich, H., Chan, C., and Moyer, C. L. (2007). A novel lineage of proteobacteria involved in formation of marine Fe-oxidizing microbial mat communities. PLoS
ONE 2, e667. doi: 10.1371/journal.pone. 0000667

Friedrich, C. G. (1998). Physiology and genetics of sulfur-oxidizing bacteria. Adv. Microb. Physiol. 39, 235-289.

Friedrich, C. G., Bardischewsky, F., Rother, D., Quentmeier, A., and Fischer, J. (2005). Prokaryotic sulfur oxidation. Curr. Opin. Microbiol. 8, 253-259.

Friedrich, C. G., Quentmeier, A., Bardischewsky, F., Rother, D., Orawski, G., Hellwig, P., and Fischer, J. (2008) "Redox control of chemotrophic sulfur oxidation of Paracoccus pantotrophus," in Microbial Sulfur Metabolism, eds C. Dahl and C. G. Friedrich (Heidelberg: Springer), 139-150. chewsky, F., Quentmeier, A., and Fischer, J. (2001). Oxidation of reduced inorganic sulfur compounds by bacteria: emergence of a common mechanism? Appl. Environ. Microbiol. 67, 2873-2882.

Frigaard, N. U., and Dahl, C. (2009). Sulfur metabolism in phototrophic sulfur bacteria. Adv. Microb. Physiol. 54, 103-200.

Ghosh, W., and Dam, B. (2009). Biochemistry and molecular biology of onomically and ecologically diverse bacteria and archaea. FEMS Microbiol. Rev. 33, 999-1043.

Gregersen, L. H., Bryant, D. A., and Frigaard, N. U. (2011). Mechanisms and evolution of oxidative sulfur metabolism in green sulfur bacteria. Front. Microbiol. 2:116. doi: 10.3389/fmicb.2011.00116

Grzymski, J. J., Murray, A. E., Campbell, B. J., Kaplarevic, M., Gao, G. R., Lee, C., Daniel, R., Ghadiri, A., Feldman, R. A., and Cary, S. C. (2008). Metagenome analysis of an extreme microbial symbiosis reveals eurythermal adaptation and metabolic flexibility. Proc. Natl. Acad. Sci. U.S.A. 105, 17516-17521.

Hedderich, R., Klimmek, O., Kroger, A., Dirmeier, R., Keller, M., and Stetter, K. O. (1999). Anaerobic respiration with elemental sulfur and with
Friedrich, C. G., Rother, D., Bardislithotrophic sulfur oxidation by tax-

and Desulfurococcaceae) will be important for understanding the biogeochemical processes and energy- and elemental fluxes of sulfur compounds in the deep-sea hydrothermal environments (Reysenbach et al., 2000, 2002; Teske et al., 2002; Takai et al., 2003a). Recently, genetic information has been rapidly accumulating and has been providing the important genetic potential for understanding the complex sulfur-related metabolic networks in deep-sea hydrothermal vent ecosystems. In contrast, enzymatic and biochemical data are highly insufficient to clarify the in vivo and in situ kinetics, operation and control of metabolic pathways. These will be an important focus for future studies.

disulfides. FEMS Microbiol. Rev. 22, 353-381.

Holkenbrink, C., Ocon Barbas, S., Mellerup, A., Otaki, H., and Frigaard, N. U. (2011). Sulfur globule oxidation in green sulfur bacteria is dependent on the dissimilatory sulfite reductase system. Microbiology $157,1229-1239$

Hügler, M., Gartner, A., and Imhoff, J. F. (2010). Functional genes as markers for sulfur cycling and $\mathrm{CO} 2$ fixation in microbial communities of hydrothermal vents of the Logatchev field. FEMS. Microbiol. Ecol. 73, 526-537.

Inagaki, F., Takai, K., Kobayashi, H., Nealson, K. H., and Horikoshi, K. (2003). Sulfurimonas autotrophica gen. nov., sp. nov., a novel sulfuroxidizing epsilon-proteobacterium isolated from hydrothermal sediments in the Mid-Okinawa Trough. Int. J. Syst. Evol. Microbiol. 53, 1801-1805.

Inagaki, F., Takai, K., Nealson, K. H., and Horikoshi, K. (2004). Sulfurovum lithotrophicum gen. nov., sp. nov., a novel sulfur-oxidizing chemolithoautotroph within the epsilon-Proteobacteria isolated from Okinawa Trough hydrothermal sediments. Int. J. Syst. Evol. Microbiol. 54, 1477-1482.

Jannasch, H. W., and Mottl, M. J. (1985). Geomicrobiology of deepsea hydrothermal vents. Science 229 , 717-725.

Jeanthon, C. (2000). Molecular ecology of hydrothermal vent microbial communities. Antonie Van Leeuwenhoek 77, 117-133.

Kappler, U., and Dahl, C. (2001). Enzymology and molecular biology of prokaryotic sulfite oxidation. FEMS Microbiol. Lett. 203, 1-9.

Kletzin, A., Urich, T., Muller, F., Bandeiras, T. M., and Gomes, C. M. (2004). Dissimilatory oxidation and reduction of elemental sulfur in thermophilic archaea. J. Bioenerg. Biomembr. 36, 77-91.

Kuever, J., Sievert, S. M., Stevens, H., Brinkhoff, T., and Muyzer, G. (2002).
Microorganisms of the oxidative and reductive part of the sulphur cycle at a shallow-water hydrothermal ven in the Aegean Sea (Milos, Greece). Cah. Biol. Mar. 43, 413-416.

Kusai, K., and Yamanaka, T. (1973). The oxidation mechanisms of thiosulphate and sulphide in Chlorobium thiosulphatophilum: roles of cytochrome c-551 and cytochrome c-553. Biochim. Biophys. Acta 325, 304-314.

Kuwahara, H., Yoshida, T., Takaki, Y., Shimamura, S., Nishi, S., Harada, M., Matsuyama, K., Takishita, K., Kawato, M., Uematsu, K., Fujiwara Y., Sato, T., Kato, C., Kitagawa, M., Kato, I., and Maruyama, T. (2007). Reduced genome of the thioautotrophic intracellular symbiont in a deep-sea clam, Calyptogena okutanii. Curr. Biol. 17, 881-886.

Kvenvolden, K. A., Weliky, K., Nelson, H., and Marais, D. J. (1979). Submarine seep of carbon dioxide in Norton sound, Alaska. Science 205 , 1264-1266

Marcia, M., Ermler, U., Peng, G. H., and Michel, H. (2010). A new structure-based classification of sulfide:quinone oxidoreductases. Proteins 78, 1073-1083.

McCollom, T. M., and Shock, E. L. (1997). Geochemical constraints on chemolithoautotrophic metabolism by microorganisms in seafloor hydrothermal systems. Geochim. Cosmochim. Acta. 61, 4375-4391.

Muyzer, G., and Stams, A. J. (2008). The ecology and biotechnology of sulphate-reducing bacteria. Nat Rev. Microbiol. 6, 441-454.

Mußmann, M., Hu, F. Z., Richter, M., De Beer, D., Preisler, A., Jorgensen, B. B. Huntemann, M., Glöckner, F. O. Amann, R., Koopman, W. J., Lasken, R. S., Janto, B., Hogg, J., Stoodley, P., Boissy, R., and Ehrlich, G. D. (2007). Insights into the genome of large sulfur bacteria revealed by analysis of single filaments. PLoS Biol. 5, e230. doi: 10.1371/journal.pbio.0050230

Nakagawa, S., and Takai, K. (2008). Deep-sea vent chemoautotrophs: 
diversity, biochemistry and ecological significance. FEMS. Microbiol. Ecol. 65, 1-14.

Nakagawa, S., Takai, K., Inagaki, F., Hirayama, H., Nunoura, T., Horikoshi, K., and Sako, Y. (2005). Distribution, phylogenetic diversity and physiological characteristics of epsilon-Proteobacteria in a deep-sea hydrothermal field. Environ. Microbiol. 7, 1619-1632.

Nakagawa, S., Takaki, Y., Shimamura, S., Reysenbach, A. L., Takai, K., and Horikoshi, K. (2007). Deep-sea vent epsilon-proteobacterial genomes provide insights into emergence of pathogens. Proc. Natl. Acad. Sci. U.S.A. 104, 12146-12150.

Nealson, K. H., Inagaki, F., and Takai, K. (2005). Hydrogen-driven subsurface lithoautotrophic microbial ecosystems (SLiMEs): do they exist and why should we care? Trends Microbiol. 13, 405-410.

Nelson, D. C., and Castenholz, R. W. (1981). Use of reduced sulfurcompounds by Beggiatoa sp. J. Bacteriol. 147, 140-154.

Newton, I. L., Woyke, T., Auchtung, T. A., Dilly, G. F., Dutton, R. J., Fisher, M. C. Fontanez, K. M., Lau, E., Stewart, F. J., Richardson, P. M., Barry, K. W., Saunders, E., Detter, J. C., $\mathrm{Wu}, \mathrm{D}$., Eisen, J. A., and Cavanaugh, C. M. (2007). The Calyptogena magnifica chemoautotrophic symbiont genome. Science 315, 998-1000.

Numoto, N., Nakagawa, T., Kita, A., Sasayama, Y., Fukumori, Y., and Miki, K. (2005). Structure of an extracellular giant hemoglobin of the gutless beard worm Oligobrachia mashikoi. Proc. Natl. Acad. Sci. U.S.A. 102, 14521-14526.

Oh-oka, H., and Blankenship, R. E. (2004). "Green bacteria: secondary electron donor (cytochromes)," in Encyclopedia of Biological Chemistry, eds W. J. Lennarz and M. D. Lane (Boston, MA: Elsevier), 321-324.

Pfennig, N., and Biebel, H. (1986). "The dissimilatory sulfate-reducing bacteria," in The Prokaryotes: A Handbook on Habitats, Isolation and Identification of Bacteria, ed. M. P. Starr (Heidelberg: Springer), 928-940.

Reinartz, M., Tschape, J., Bruser, T., Truper, H. G., and Dahl, C. (1998). Sulfide oxidation in the phototrophic sulfur bacterium Chromatium vinosum. Arch. Microbiol. 170, 59-68.

Reysenbach, A. L., Gotz, D., Banta, A., Jeanthon, C., and Fouquet, Y. (2002). Expanding the distribution of the Aquificales to the deep-sea vents on Mid-Atlantic Ridge and Central Indian Ridge. Cah. Biol. Mar. 43, 425-428.
Reysenbach, A. L., Longnecker, K., and Kirshtein, J. (2000). Novel bacterial and archaeal lineages from an in situ growth chamber deployed at a Mid-Atlantic Ridge hydrothermal vent. Appl. Environ. Microbiol. 66, 3798-3806.

Robidart, J. C., Bench, S. R., Feldman, R. A., Novoradovsky, A., Podell, S. B., Gaasterland, T., Allen, E. E., and Felbeck, H. (2008). Metabolic versatility of the Riftia pachyptila endosymbiont revealed through metagenomics. Environ. Microbiol. $10,727-737$.

Schmidt, T. M., Arieli, B., Cohen, Y., Padan, E., and Strohl, W. R. (1987). Sulfur metabolism in Beggiatoa alba. J. Bacteriol. 169, 5466-5472.

Scott, K. M., Sievert, S. M., Abril, F. N., Ball, L. A., Barrett, C. J., Blake, R. A., Boller, A. J., Chain, P. S., Clark, J. A., Davis, C. R., Detter, C., Do, K. F., Dobrinski, K. P., Faza, B. I., Fitzpatrick, K. A., Freyermuth, S. K., Harmer, T. L., Hauser, L. J., Hügler, M., Kerfeld, C. A., Klotz, M. G., Kong, W. W., Land, M., Lapidus, A., Larimer, F. W., Longo, D. L., Lucas, S., Malfatti, S. A., Massey, S. E., Martin, D. D., McCuddin, Z., Meyer, F., Moore, J. L., Ocampo, L. H. Jr., Paul, J. H., Paulsen, I. T., Reep, D. K., Ren, Q., Ross, R. L., Sato, P. Y., Thomas, P., Tinkham, L. E., and Zeruth, G. T. (2006). The genome of deep-sea vent chemolithoautotroph Thiomicrospira crunogena XCL-2. PLoS Biol. 4, e383. doi: 10.1371/journal.pbio.0040383

Shahak, Y., and Hauska, G. (2008). "Sulfide oxidation from cyanobacteria to humans: sulfide - quinone oxidoreductase (SQR)," in Sulfur Metabolism in Phototrophic Organisms, eds R. Hell, C. Dahl, D. B. Knaff, and T. Leustek (Dordrecht: Springer), 319-335.

Sievert, S. M., Scott, K. M., Klotz, M. G., Chain, P. S. G., Hauser, L. J., Hemp, J. Hügler, M., Land, M., Lapidus, A., Larimer, F. W., Lucas, S., Malfatti, S. A., Meyer, F., Paulsen, I. T., Ren, Q., Simon, J., and USF Genomics Class. (2008). Genome of the epsilonproteobacterial chemolithoautotroph Sulfurimonas denitrificans. Appl. Environ. Microbiol. 74, 1145-1156.

Stewart, F. J., Newton, I. L., and Cavanaugh, C. M. (2005). Chemosynthetic endosymbioses: adaptations to oxic-anoxic interfaces. Trends Microbiol. 13, 439-448.

Suzuki, Y., Sasaki, T., Suzuki, M., Nogi, Y., Miwa, T., Takai, K., Nealson, K. H., and Horikoshi, K. (2005). Novel chemoautotrophic endosymbiosis between a member of the Epsilonproteobacteria and the hydrothermal-vent gastropod Alviniconcha aff. hessleri (Gastropoda: Provannidae) from the Indian Ocean. Appl. Environ. Microbiol. 71, 5440-5450.

Takai, K., Campbell, B. J., Cary, S. C., Suzuki, M., Oida, H., Nunoura, T., Hirayama, H., Nakagawa, S., Suzuki, Y., Inagaki, F., and Horikoshi, K. (2005). Enzymatic and genetic characterization of carbon and energy metabolisms by deep-sea hydrothermal chemolithoautotrophic isolates of Epsilonproteobacteria. Appl. Environ. Microbiol. 71, 7310-7320.

Takai, K., Gamo, T., Tsunogai, U. Nakayama, N., Hirayama, H., Nealson, K. H., and Horikoshi, K. (2004). Geochemical and microbiological evidence for a hydrogen-based, hyperthermophilic subsurface lithoautotrophic microbial ecosystem (HyperSLiME) beneath an active deep-sea hydrothermal field. Extremophiles 8, 269-282.

Takai, K., Kobayashi, H., Nealson, K. H. and Horikoshi, K. (2003a). Deferribacter desulfuricans sp. nov., a novel sulfur-, nitrate- and arsenatereducing thermophile isolated from a deep-sea hydrothermal vent. Int. J. Syst. Evol. Microbiol. 53, 839-846.

Takai, K., Inagaki, F., Nakagawa, S., Hirayama, H., Nunoura, T., Sako, Y., Nealson, K. H., and Horikoshi, K. (2003b). Isolation and phylogenetic diversity of members of previously uncultivated epsilon-proteobacteria in deep-sea hydrothermal fields. FEMS Microbiol. Lett. 218, 167-174.

Takai, K., Miyazaki, M., Hirayama, H., Nakagawa, S., Querellou, J., and Godfroy, A. (2009). Isolation and physiological characterization of two novel, piezophilic, thermophilic chemolithoautotrophs from a deep-sea hydrothermal vent chimney. Environ. Microbiol. 11, 1983-1997.

Takai, K., Nakagawa, S., Reysenbach, A.-L., and Hoek, J. (2006a). Microbial ecology of mid-ocean ridges and back-arc basins. Geophys. Monogr. Ser. 166, 185-213.

Takai, K., Nakamura, K., Suzuki, K., Inagaki, F., Nealson, K. H., and Kumagai, H. (2006b). Ultramafics-HydrothermalismHydrogenesis-HyperSLiME (UltraH3) linkage: a key insight into early microbial ecosystem in the Archean deep-sea hydrothermal systems. Paleontol. Res. 10, 269-282.

Takai, K., Miyazaki, M., Nunoura, T., Hirayama, H., Oida, H., Furushima, Y., Yamamoto, H., and Horikoshi, K. (2006c). Sulfurivirga caldicuralii gen. nov., sp. nov., a novel microaerobic, thermophilic, thiosulfate-oxidizing chemolithoautotroph, isolated from a shallow marine hydrothermal system occurring in a coral reef, Japan. Int. J. Syst. Evol. Microbiol. 56, 1921-1929.

Teske, A., Hinrichs, K. U., Edgcomb, V., de Vera Gomez, A., Kysela, D., Sylva, S. P., Sogin, M. L., and Jannasch, H. W. (2002). Microbial diversity of hydrothermal sediments in the Guaymas Basin: evidence for anaerobic methanotrophic communities. Appl. Environ. Microbiol. 68, 1994-2007.

Urakawa, H., Dubilier, N., Fujiwara, Y., Cunningham, D. E., Kojima, S., and Stahl, D. A. (2005). Hydrothermal vent gastropods from the same family (Provannidae) harbour epsilon- and gammaproteobacterial endosymbionts. Environ. Microbiol. 7, 750-754.

Wolin, M. J., Wolin, E. A., and Jacobs, N. J. (1961). Cytochrome-producing anaerobic Vibrio succinogenes, sp. n. J. Bacteriol. 81, 911-917.

Yamamoto, M., Nakagawa, S., Shimamura, S., Takai, K., and Horikoshi, K. (2010). Molecular characterization of inorganic sulfur-compound metabolism in the deep-sea epsilonproteobacterium Sulfurovum sp. NBC37-1. Environ. Microbiol. 12, 1144-1153.

Zal, F., Leize, E., Lallier, F. H., Toulmond, A., Van Dorsselaer, A., and Childress, J. J. (1998). S-Sulfohemoglobin and disulfide exchange: the mechanisms of sulfide binding by Riftia pachyptila hemoglobins. Proc. Natl. Acad. Sci. U.S.A. 95, 8997-9002.

Conflict of Interest Statement: The authors declare that the research was conducted in the absence of any commercial or financial relationships that could be construed as a potential conflict of interest.

Received: 03 March 2011; accepted: 30 August 2011; published online: 20 September 2011.

Citation: Yamamoto $M$ and Takai $K$ (2011) Sulfur metabolisms in epsilonand gamma-Proteobacteria in deep-sea hydrothermal fields. Front. Microbio 2:192. doi: 10.3389/fmicb.2011.00192 This article was submitted to Frontiers in Microbial Physiology and Metabolism, a specialty of Frontiers in Microbiology. Copyright () 2011 Yamamoto and Takai. This is an open-access article subject to a non-exclusive license between the authors and Frontiers Media SA, which permits use, distribution and reproduction in other forums, provided the original authors and source are credited and other Frontiers conditions are complied with. 